\title{
Efficacy and Safety of Insulin Glargine in Type 2 Diabetic Patients with Renal Failure
}

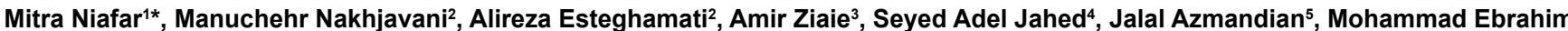
Khamseh ${ }^{2}$, Gholamreza Yousefzadeh ${ }^{5}$, Mohammad Hassan Gozashti ${ }^{5}$ and Mojtaba Malek ${ }^{2}$

$1 /$ mam Reza Hospital, Tabriz University of Medical Sciences, Tabriz, Iran

${ }^{2}$ Tehran University of Medical Sciences

${ }^{3}$ Ghazvin University of Medical Sciences

${ }^{4}$ Booali General Hospital, Islamic Azad University, Tehran Medical Branch, Iran

${ }^{5}$ Kerman University of Medical Sciences

\begin{abstract}
Aim and Background: In patients with type 2 diabetes mellitus complicated with renal failure achieving good glucose control and reduction of risk of hypoglycemia should be balanced. The aim of this study was to determine the safety and efficacy of insulin glargine in type 2 diabetic patients with diabetic nephropathy.

Methods: A total of 89 subjects with type 2 diabetes (mean age $62.9 \pm 10.7$ and diabetes duration $13.9 \pm 7.6$ years) who had diabetic nephropathy (mean Glomerular FiltrationR [GFR] $34.1 \pm 11.5 \mathrm{ml} / \mathrm{min}$ ) were included in the study. Patients who were not optimally controlled or experienced frequent hypoglycemia on Oral Antidiabetic Drugs (OAD) or NPH insulin received insulin glargine at bedtime. The starting dose was 0.1 unit $/ \mathrm{Kg}$ and adjusted to obtain target fasting blood glucose (5-7.2 mmol/l). The medical records were obtained before and 2 and 4 months after beginning insulin glargine.

Results: At the end of four month treatment period, significant reduction in glycated hemoglobin $\left(\mathrm{HbA}_{1} \mathrm{c}\right)$ was observed (from $8.4 \% \pm 1.6$ to $7.7 \% \pm 1.2)(p<0.001)$.

The treatments were associated with significant reduction in fasting glucose levels (from $159.7 \pm 67$ to $119.4 \pm$ $28.4 \mathrm{mg} / \mathrm{dl})(\mathrm{p}<0.001)$.Patients' Body Mass Index (BMI) did not increase at the end of study $(26.2 \pm 3.9$ and $26.2 \pm 3.8$ $\left.\mathrm{kg} / \mathrm{m}^{2}\right)(\mathrm{p}=0.96)$. Mild symptomatic hypoglycemia was seen in $12.5 \%$ of subjects. No other side effects were noted throughout the study.
\end{abstract}

Conclusion: Insulin glargine improved $\mathrm{HbA} 1 \mathrm{c}$ at short-term and proved to be safe and well tolerated in type 2 diabetic patients with diabetic nephropathy.

Keywords: Insulin glargine; Diabetic nephropathy; Hypoglycemia

\section{Introduction}

The increasing prevalence, variable pathogenesis, progressive natural history, and complications of Type 2 Diabetes Mellitus (T2DM) emphasize the urgent need for new treatment strategies [1,2]. T2DM is a metabolic disease that is diagnosed on the basis of sustained hyperglycemia. Patients with T2DM are at increased risk of serious health problems, including cardiovascular disease, blindness, renal failure, orthopedic, and mental disorders [3-5]. Diabetic nephropathy occurs in almost $40 \%$ of patients with diabetes and is single leading cause of end-stage renal diseases. Large studies have shown that one third of the patients on hemodialysis or renal transplant recipients are diabetics [6]. Moreover patients with diabetic nephropathy, especially with type 2 diabetes, have a high cardiovascular risk. Once diabetic nephropathy is established and renal failure has started, specialists should consider what the blood glucose objectives are for the patient and which drugs should be chosen to achieve them [7] to reduce microvascular and macrovascular complications [8]

Ideal insulin therapies in diabetic patients with advanced renal failure are difficult to establish given the lack of pharmacokinetic studies for the various types of insulin in patients with different degrees of renal insufficiency $[9,10]$. Avoidance of long-acting insulin preparations has been recommended in patients with advanced renal failure by some authors [11], while others support the use of such preparations [12].

The long-acting insulin analogs have relatively flat pharmacokinetic profiles and a longer duration of action [13]. Insulin glargine has been reported as safe and effective in improving glycemic control in severe
T2DM patients [14]. It provides an effective basal insulin supply when administered once daily in patients with type 2 diabetes $[15,16]$ and reduces the risk of nocturnal hypoglycemia compared with NPH insulin, with at least equivalent glycemic control in type 2 diabetes $[14,17]$. Although insulin analogues are commonly prescribed for the management of diabetes mellitus, there is uncertainty regarding their optimal use especially in complicated patients [5]. This study aimed to determine the safety and efficacy of insulin glargine in type 2 diabetic patients with diabetic nephropathy.

\section{Materials and Methods}

This pilot multi-center clinical trial was conducted in the diabetes clinic of 4 medical centers including Tehran, Tabriz, Ghazvin and Kerman Universities on "patients with type 2 diabetes mellitus complicated with renal failure" since May-2010 to April-2011.

*Corresponding author: Mitra Niafar, Associate Professor, Endocrinology and Metabolism Section, Department of Medicine, Imam Reza Hospital, Tabriz University of Medical Sciences, Tabriz, Iran, Tel: 00989143113036; Fax: 0098(411)3357580; E-mail: dr_niafar@yahoo.com, niafarm@tbzmed.ac.ir

Received February 24, 2012; Accepted April 16, 2012; Published April 20, 2012

Citation: Niafar M, Nakhjavani M, Esteghamati A, Ziaie A, Jahed SA, et al. (2012) Efficacy and Safety of Insulin Glargine in Type 2 Diabetic Patients with Renal Failure. J Diabetes Metab 3:189. doi:10.4172/2155-6156.1000189

Copyright: $\odot 2012$ Niafar M, et al. This is an open-access article distributed unde the terms of the Creative Commons Attribution License, which permits unrestricted use, distribution, and reproduction in any medium, provided the original author and source are credited. 
A total of 89 patients with type 2 diabetes mellitus, aged 40 to 80 years, and creatinine clearance less than $50 \mathrm{ml} / \mathrm{min}$ (based on Cockroft-Gault formulae) were included in the study [18]. Subjects were excluded for any of the following criteria: patients with hepatic failure, those undergoing hemodialysis or peritoneal dialysis, patients with type 1 diabetes mellitus, and pregnancy.

The study was confirmed by ethic committee of Tabriz University of Medical Sciences and all enrolled patients gave written informed consent before participation. Entry criteria included those who were either not optimally controlled on OAD or had frequent hypoglycemic episodes on NPH insulin received bedtime glargine $0.1 \mathrm{u} / \mathrm{Kg}$. Patients were instructed on proper self-monitoring technique and in the first step using the dose titration schedule target Fasting Blood Sugar (FBS) level was set to be $90-130 \mathrm{mg} / \mathrm{dl}$. The insulin glargine dose was titrated every three days according to self-monitored fasting plasma glucose levels by increasing 2 units every 3 days to meet target values.

In the next step Pre-Prandial (PP) Blood Sugar (BS) was checked twice a day (pre-lunch and pre-dinner, 3 times per week) and if necessary (BS $>140)$, regular insulin was administered with dose of $0.05 \mathrm{unit} / \mathrm{kg}$ as pre-meal and was increased until the pre-prandial BS reached to $100-140 \mathrm{mg} / \mathrm{dl}$. Patients were instructed to measure fasting blood glucose or pre-prandial glucose 6 times per week.

Baseline characteristics of all participants including demographic data were recorded (age, sex, BMI and history of diabetes). Blood samples were checked for FBS, $\mathrm{HbA}_{1} c$, Blood Urea Nitrogen (BUN), Creatinine, sodium (Na), potassium $(\mathrm{K})$, Cholesterol, triglyceride, High Density Lipoprotein (HDL), and Low Density Lipoprotein (LDL). Glucose was measured using "Arkray Glucocard 01 Meter Kit" made in Japan. The method is based on interactions with Glucose Oxidase (GOx) which is standard enzyme for biosensors, it has a relatively higher selectivity for glucose [19]. The Diazyme Direct Enzymatic $\mathrm{HbA}_{1} \mathrm{c}$ reagent was used for measurement of glycated hemoglobin, and the measured variable was expressed as $\% \mathrm{HbA}_{1} \mathrm{c}$.

Minor hypoglycemia was defined as plasma glucose less than 3.1 $\mathrm{mmol} / \mathrm{L}$ and major hypoglycemia was determined by hypoglycemia requiring third-party assistance [20].

The medical records were obtained three times during the study: first at baseline and then two and four months after administration of insulin glargine. All patients were visited weekly during which any episode of hypoglycaemia (minor or major, if present) was recorded. All baseline laboratory tests were repeated at the end of fourth month.

\section{Statistical analysis}

The obtained data were analysed by SPSS-16 statistical Software (SPSS Science, Chicago, IL).The paired t-test and the Repeated Measurement of ANOVA test were used to compare the patient's variables during the study before and after treatment. The P-values less than 0.05 were considered significant.

\section{Results}

A total of 89 subjects ( 54 male and 35 female) who had diabetic nephropathy (mean GFR $34.1 \pm 11.5 \mathrm{ml} / \mathrm{min}$ ) were included in the study.

The mean age of the patients and the mean duration of disease were $62.9 \pm 10.7$ and $13.9 \pm 7.6$ years, respectively.

Nearly half of the participants were taking sulfonylurea, $20 \%$ used metformin and other OADs were used in $10 \%$ of patients. Forty five percent of them had been treated by human insulin and $6.6 \%$ were on insulin plus $\mathrm{OAD}$. Long term complications including retinopathy (58.7\%), neuropathy (59.3\%), Coronary Artery Disease (CAD) (30.4\%), Cerebral Vascular Disease CVD (4.3\%) and Peripheral Vascular Disease (PVD) (2.2\%), were detected at baseline. The prevalence of chronic complications did not change during the study period ( $p>0.05)$. Table 1 shows the patients' characteristics at the baseline and end of the study period.

At the end of four-month treatment period, significant reduction in $\mathrm{HbA}_{1} \mathrm{c}(\mathrm{p}<0.05)$ and fasting glucose levels $(\mathrm{p}<0.05)$ were observed. Also our study showed that the significant increase in patients' GFR $(p=0.04)$.No increment in body mass index was seen at the end of fourmonth of therapy $(\mathrm{p}=0.96)$. Mild symptomatic hypoglycemia was seen in $12.5 \%$ of subjects. No other side effects were noted throughout the study.

During the first 2 months of the study 6 episodes of minor hypoglycemia and 2 episodes of major hypoglycemia were recorded in the patients receiving combined regular insulin and glargine. At the end of study 4 episodes of minor hypoglycemia and 3 episodes of night time major hypoglycemia were detected in the patients receiving combined regular insulin and glargine.

Totally, regardless of the type of insulin used by patients (glargine with or without regular insulin) hypoglycemic episodes occurred in $12.5 \%$ of cases.

At the end of the fourth month, $41 \%$ of the patients needed combination of regular insulin and insulin glargine and 59\% were using glargine alone.

The mean daily dose of insulin glargine was $19.4 \pm 8.2$ units/day and the mean of total (regular and glargine) insulin in the subjects of the study was $24.4 \pm 12$ units/day.

Twelve patients needed short acting insulin with mean dose of 6.4 \pm 3.5 units once a day ( 5 patients in pre-breakfast, 4 patients in prelunch and 3 patients in pre-dinner time).

Regular insulin with mean dose of $15 \pm 8.6$ units was administered in 24 patients twice daily (13 patients in pre-breakfast and pre-dinner, 6 patients in pre-lunch and pre-dinner and 5 patients in pre-breakfast and pre-lunch time).

\begin{tabular}{cccc}
\hline Variable & Baseline & 4 month later P- value \\
\hline $\mathrm{BMl}\left(\mathrm{kg} / \mathrm{m}^{2}\right)$ & $26.2 \pm 3.9$ & $26.2 \pm 3.8$ & 0.96 \\
\hline Systolic BP $(\mathrm{mmHg})$ & $137.8 \pm 19.8$ & $137.8 \pm 20.4$ & 0.49 \\
\hline Diastolic BP $(\mathrm{mmHg})$ & $82.4 \pm 10.9$ & $82.7 \pm 11.2$ & 0.78 \\
\hline $\mathrm{BUN}(\mathrm{mg} / \mathrm{dl})$ & $57.5 \pm 27.2$ & $56.6 \pm 26$. & 0.77 \\
\hline Creatinine $(\mathrm{mg} / \mathrm{dl})$ & $2.3 \pm 0.9$ & $2.4 \pm 1.4$ & 0.3 \\
\hline $\mathrm{K}^{+}(\mathrm{mg} / \mathrm{dl})$ & $4.8 \pm 0.6$ & $4.7 \pm 0.5$ & 0.15 \\
\hline $\mathrm{Na}^{+}(\mathrm{mg} / \mathrm{dl})$ & $139.8 \pm 4$ & $139.7 \pm 3.1$ & 0.28 \\
\hline $\mathrm{GFR}(\mathrm{ml} / \mathrm{min})$ & $34.1 \pm 11.5$ & $36.2 \pm 14.8$ & 0.04 \\
\hline $\mathrm{TG}(\mathrm{mg} / \mathrm{dl})$ & $181.8 \pm 86.7$ & $163.4 \pm 80$ & 0.03 \\
\hline $\mathrm{Cholesterol}(\mathrm{mg} / \mathrm{dl})$ & $177.4 \pm 47.6$ & $175 \pm 49.1$ & 0.54 \\
\hline $\mathrm{LDL}(\mathrm{mg} / \mathrm{dl})$ & $98.2 \pm 34.6$ & $92.4 \pm 33.7$ & 0.13 \\
\hline $\mathrm{HDL}(\mathrm{mg} / \mathrm{dl})$ & $41.1 \pm 20$ & $42 \pm 10.3$ & 0.01 \\
\hline $\mathrm{FBS}(\mathrm{mg} / \mathrm{dl})$ & $159.7 \pm 67$ & $119.4 \pm 28.4$ & 0.0001 \\
\hline $\mathrm{HbA} \mathrm{c}(\%)$ & $8.4 \pm 1.6$ & $7.7 \pm 1.2$ & 0.001 \\
\hline
\end{tabular}

Note: BMI: Body Mass Index; BP: Blood Pressure; BUN: Blood Urea Nitrogen; GFR: Glomerular Filtration Rate; K: Potassium; Na: Sodium; TG: Triglyceride; LDL: Low Density Lipoprotein; HDL: High Density Lipoprotein; FBS: Fasting Blood Sugar; $\mathrm{HbA}_{1} \mathrm{c}$ : Glycated Hemoglobin

Table 1: Comparison of patients variables during the study. 


\section{Discussion}

In this study, $\mathrm{HbA}_{1} \mathrm{c}$ values were found to be significantly reduced in study subject's and regardless of avoiding tight glycemic control, significant increase was seen in GFR. Hemoglobin A c level is correlated with cardiovascular events in the patients with type 2 diabetes. ACCORD study showed that, as compared with standard therapy, the use of intensive therapy to target normal hemoglobin $\mathrm{A}_{1}$ c levels for 3.5 years increased mortality and did not reduce major cardiovascular events significantly [4]. These findings confirm the harm of intensive glucose lowering in high-risk patients with type 2 diabetes.

We did not use tight control and the patients BMI did not changed during the study period although the duration of our study was very short. Indeed in our study good glycemic control favorably affects lipid profile. These findings were in agreement with the previous studies which showed similar results $[21,22]$.

Rashid et al. in a dose finding cross-sectional study enrolled 88 type 2 patients with diabetes and end stage diabetic nephropathy (stage 5) [23]. They used regular insulin, NPH insulin or pre-mixed NPH and regular insulin in the ratio of $70 \%$ and $30 \%$. In their series, mean insulin requirement was $14.8 \pm 14.6$ units/day and men required more insulin than women $(21.0 \pm 17.2$ vs.13.6 \pm 13.0 units $)$. In our patients the mean insulin requirement (regular and glargine) was $24.4 \pm 12$ units/day and women required more insulin than men (27.76 \pm 13.18 vs. $22.11 \pm 10.93$ units $)(p=0.02)$. Also, the daily dose requirement of insulin glargine was higher in women $(22.06 \pm 8.7$ vs.17.92 \pm 7.73$)$. In Rashid et al. study there was significant correlation between serum creatinine and the total units of insulin required and with increasing serum creatinine levels patients required less insulin. However, in our series, no significant relation could be found between creatinine, GFR and the total units of insulin required $(p>0.05)$. Our result seems to be consistent with results of another conducted study by Rave et al. [24]. In this study he did not find any statistically significant differences in diabetic patients with impaired renal functions as compared to diabetic controls with normal renal functions. They have shown that in contrast to the higher plasma insulin levels, the overall metabolic response to regular insulin was lower in patients with diabetic nephropathy as in diabetic control patients.

Also in our study, using linear regression model, no significant relation could be found between the patients' BMI and the total units of insulin required $(\mathrm{r}=0.18)$.

Glargine was equivalent to NPH in terms of glycemic control but had modest advantages in terms of hypoglycemia, especially nocturnal. Glargine appear to have only slight clinical advantages over NPH, but has much higher costs and does not appear to be cost-effective as firstline insulins for type 2 diabetes $[25,26]$. In clinical trials, a single daily injection of insulin glargine provides glycemic control equivalent to that afforded by NPH insulin [27], but with a lower risk of hypoglycemia [28-30]. Peterson suggested that glargine, provides better glycemic control than NPH insulin without increasing the risk of hypoglycemia [31]. In our study there is no significant increases in patient's weight despite improvement in glycemic control reflects the less frequent hypoglycemia seen with insulin glargine. Indeed poor appetite and nutritional status due to uremia may explain lack of weight gain in the present study. Clinical efficacy and safety profile of insulin analogues are not clearly defined in patients with moderate renal failure and most of the reported studies are case reports [32] or consist small series of diabetic patients on dialysis $[33,34]$.
Pscherer et al. reported the results of their study performed on 20 diabetic (4 type 1 and 16 type 2) patients with end stage renal disease on hemodialysis treated with insulin glargine [35]. In this nine-month study, $\mathrm{HbA}_{1} \mathrm{c}$ was reduced $0.9 \%(\mathrm{p}<0.01)$, severe hypoglycemic events were not reported and dry weight increased approximately $1.5 \mathrm{~kg}$. In the present study, at the end of four month treatment periods with insulin glargine the significant reduction in $\mathrm{HbA}_{1} \mathrm{c}(0.7 \%)$ and a few hypoglycemic episodes were achieved.

Our short term experience confirmed the safety and efficacy of insulin glargine in type 2 diabetic patients with diabetic nephropathy.

\section{Study Limitations}

In this study we followed the patients only for four months. It seems that studies with longer duration and precise monitoring of side effects are required.

In addition we did not compare other long acting insulin analogs with insulin glargine.

\section{Conclusions}

Insulin glargine improved $\mathrm{HbA}_{1} \mathrm{c}$ at this short-term study and proved to be safe and well tolerated in patients with type 2 diabetes and diabetic nephropathy.

\section{References}

1. Tahrani AA, Bailey CJ, Del Prato S, Barnett AH (2011) Management of type 2 diabetes: new and future developments in treatment. Lancet 378: 182-197.

2. Vigersky RA (2011) An overview of management issues in adult patients with type 2 diabetes mellitus. J Diabetes Sci Technol 5: 245-250.

3. Gudbjörnsdottir S, Eliasson B, Eeg-Olofsson K, Zethelius B, Cederholm J, et al. (2011) Additive effects glycaemia and dyslipidaemia on risk of cardiovascular diseases in type 2 diabetes: an observational study from the Swedish National Diabetes Register. Diabetologia 54: 2544-2551.

4. Action to Control Cardiovascular Risk in Diabetes Study Group, Gerstein HC Miller ME, Byington RP, Goff DC Jr, et al. (2008) Effects of intensive glucose lowering in type 2 diabetes. N Engl J Med 358: 2545-2559.

5. Singh SR, Ahmad F, Lal A, Yu C, Bai Z, et al. (2009) Efficacy and safety of insulin analogues for the management of diabetes mellitus: a meta-analysis. CMAJ 180: 385-397

6. US Renal Data System (1999) USRDS 1999 annual data report. Bethesda, Md National Institutes of Health, National Institute of Diabetes and Digestive and Kidney Disease: 25-38

7. Charpentier G, Riveline JP, Varroud-Vial M (2000) Management of drugs affecting blood glucose in diabetic patients with renal failure. Diabetes Metab 26: 73-85.

8. Sampanis Ch (2008) Management of hyperglycemia in patients with diabetes mellitus and chronic renal failure. Hippokratia 12: 22-27.

9. Snyder RW, Berns JS (2004) Use of insulin and oral hypoglycemic medications in patients with diabetes mellitus and advanced kidney disease. Semin Dial 17: $365-370$.

10. Bilous RW (2004) End-stage renal failure and management of diabetes. Diabet Med 21: 12-14.

11. Charpentier G, Riveline JP, Varroud-Vial M (2000) Management of drugs affecting blood glucose in diabetic patients with renal failure. Diabetes Metab 26: 73-85.

12. Mak RH (2000) Impact of end-stage renal disease and dialysis on glycemic control. Semin Dial 13: 4-8.

13. Reynolds LR (2010) Comparing insulins detemir and glargine in type 2 diabetes: more similarities than differences. Commentary. Postgrad Med 122: 201-203.

14. Ciardullo AV, Bacchelli M, Daghio MM, Carapezzi C (2006) Effectiveness and 
Citation: Niafar M, Nakhjavani M, Esteghamati A, Ziaie A, Jahed SA, et al. (2012) Efficacy and Safety of Insulin Glargine in Type 2 Diabetic Patients with Renal Failure. J Diabetes Metab 3:189. doi:10.4172/2155-6156.1000189

safety of insulin glargine in the therapy of complicated or secondary diabetes: clinical audit. Acta Diabetol 43: 57-60.

15. Yki-Jarvinen H, Dressler A, Ziemen M, the HOE 901/3002 Study Group (2000) Less nocturnal hypoglycemia and better post-dinner glucose control with bedtime insulin glargine compared with bedtime $\mathrm{NPH}$ insulin during insulin combination therapy in type 2 diabetes. HOE 901/3002 Study Group. Diabetes Care 23: 1130-1136

16. Riddle MC, Rosenstock J, Gerich J, Insulin Glargine 4002 Study Investigators (2003) The treat-to-target trial: randomized addition of glargine or human NPH insulin to oral therapy of type 2 diabetic patients. Diabetes Care 26: 3080-3086.

17. Rosenstock J, Dailey G, Massi-Benedetti M, Fritsche A, Lin Z, et al. (2005) Reduced hypoglycemia risk with insulin glargine: a meta-analysis comparing insulin glargine with human NPH insulin in type 2 diabetes. Diabetes Care 28 : 950-955.

18. Martinez-Castelao A, Gorriz JL, Portoles JM, De Alvaro F, Cases A, et al (2011) Baseline Characteristics of Patients with Chronic Kidney Disease Stage 3 and Stage 4 in Spain: the MERENA Observational Cohort Study. BMC Nephrol 12: 53

19. Yoo EH, Lee SY (2010) Glucose biosensors: an overview of use in clinica practice. Sensors (Basel) 10: 4558-4576.

20. Davidson JA, Liebl A, Christiansen JS, Fulcher G, Ligthelm RJ, et al. (2009) Risk for nocturnal hypoglycemia with biphasic insulin aspart 30 compared with biphasic human insulin 30 in adults with type 2 diabetes mellitus: a metaanalysis. Clin Ther 31: 1641-1651.

21. Ram VM, Gyawali P, Raut PP, Regmi P, Khelanand PS, et al. (2011) Association between glycaemic control and serum lipid profile in type 2 diabetic patients: Glycated haemoglobin as a dual biomarker. Biomedical Research 22: 375-380.

22. Khan HA, Sobki SH, Khan SA (2007) Association between glycaemic control and serum lipids profile in type 2 diabetic patients: HbA1c predicts dyslipidaemia. Clin Exp Med 7: 24-29.

23. Kamran Rashid, Khalil Ur Rehman, Saeed Anwer M, Aaeisha Qureshi, Basharat RA (2004) Insulin Requirement In Diabetic Patients with Chronic Renal Failure due to Diabetic Nephropathy (Dn). Biomedica 20.

24. Rave K, Heise T, Pfutzner A, Heinmann L, Sawicki PT (2001) Impact of diabetic nephropathy on the pharmacodynamic and pharmacokinetic properties of insulin in type 1 diabetic patients. Diabetes Care 24: 886-890
25. Waugh N, Cummins E, Royle P, Clar C, Marien M, et al. (2010) Newer agents for blood glucose control in type 2 diabetes: systematic review and economic evaluation. Health Technol Assess 14: 1-248.

26. Ray JA, Valentine WJ, Roze S, Nicklasson L, Cobden D, et al. (2007) Insulin therapy in type 2 diabetes patients failing oral agents: cost-effectiveness of biphasic insulin aspart $70 / 30$ vs. insulin glargine in the US. Diabetes Obes Metab 9: 103-113.

27. Home PD, Rosskamp R, Forjanic-Klapproth J, Dressler A, European Insulin Glargine Study Group (2005) A randomized multicentre trial of insulin glargine compared with NPH insulin in people with type 1 diabetes. Diabetes Metab Res Rev 21: 545-553.

28. Rosenstock J, Fonseca V, McGill JB, Riddle M, Hallé JP, et al. (2009) Similar progression of diabetic retinopathy with insulin glargine and neutral protamine Hagedorn (NPH) insulin in patients with type 2 diabetes: a long-term, randomised, open-label study. Diabetologia 52: 1778-1788.

29. Mullins $P$, Sharplin $P$, Yki-Jarvinen $H$, Riddle MC, Haring HU (2007) Negative binomial meta-regression analysis of combined glycosylated hemoglobin and hypoglycemia outcomes across eleven phase III and IV studies of insulin glargine compared with neutral protamine Hagedorn insulin in type 1 and type 2 diabetes mellitus. Clin Ther 29: 1607-1619.

30. Riddle MC, Rosenstock J, Gerich J, Insulin Glargine 4002 Study Investigators (2003) The treat-to-target trial: randomized addition of glargine or human NPH insulin to oral therapy of type 2 diabetic patients. Diabetes Care 26: 3080-3086.

31. Peterson GE (2006) Intermediate and long-acting insulins: a review of NPH insulin, insulin glargine and insulin detemir. Curr Med Res Opin 22: 2613-2619.

32. Ersoy A, Ersoy C, Altinay T (2006) Insulin analogue usage in a hemodialysis patient with type 2 diabetes mellitus. Nephrol Dial Transplant 21: 553-554.

33. Aisenpreis U, Pfutzner A, Giehl M, Keller F, Jehle PM (1999) Pharmacokinetics and pharmacodynamics of insulin lispro compared with regular insulin in hemodialysis patients with diabetes mellitus. Nephrol Dial Transplant 14: 5-6.

34. Czock D, Aisenpreis U, Rasche FM, Jehle PM (2003) Pharmacokinetics and pharmacodynamics of lispro-insulin in hemodialysis patients with diabetes mellitus. Int J Clin Pharmacol Ther 41: 492-497.

35. Pscherer S, Schreyer-Zell G, Gottsmann M (2002) Experience with insulin glargine in patients with end-stage renal disease. Diabetes 216: A53. 